\title{
EUROPA VS. USA DELAY AND THE AVIATION INDUSTRY
}

\author{
Nikolett Zoványi
}

\begin{abstract}
Because of information asymmetry in the aviation sector passengers and air carriers will never be in possession of the same facts. Passengers are exposed to carriers when they are waiting for their flights. That is the main reason why the legislative bodies have to take care of passengers by providing them rights against carriers, although there is a significant difference in the method of regulation in the United States of America and the European Union. This essay intends to point out some of them.
\end{abstract}

Keywords: aviation, ECJ, Montreal Convention, air passenger rights

\section{Introduction}

Aviation became a wildly accepted form of travel and transportation during the $20^{\text {th }}$ century. State legislative bodies realized that operating aircrafts and conducting activities in the aviation business qualify as dangerous activities, so the aviation sector needed a set of safety and liability rules to guarantee safety to passengers. In 1929 a conference was held in Warsaw where participating states adopted an international convention about the unification of certain rules relating to international carriage by air. Over the years, more than 130 states ratified the convention. In 1999 the Montreal Convention revisited the Warsaw Convention rules and implied minor changes in its text. Although there are multiple legislative products in both the international and domestic level related to aviation, in the beginning of the $21^{\text {st }}$ century a new approach came into the picture. This new phenomenon is the recognition of passenger rights, whether states should provide more powerful rights to passengers and protect their interests during the flight.

\section{Latest Trends in Air Passenger Preferences}

9/11 was a big turmoil in the aviation sector too, and air traffic decreased significantly as a consequence of the attacks. 
Figure 1

The World Aviation - 1950 to 2012

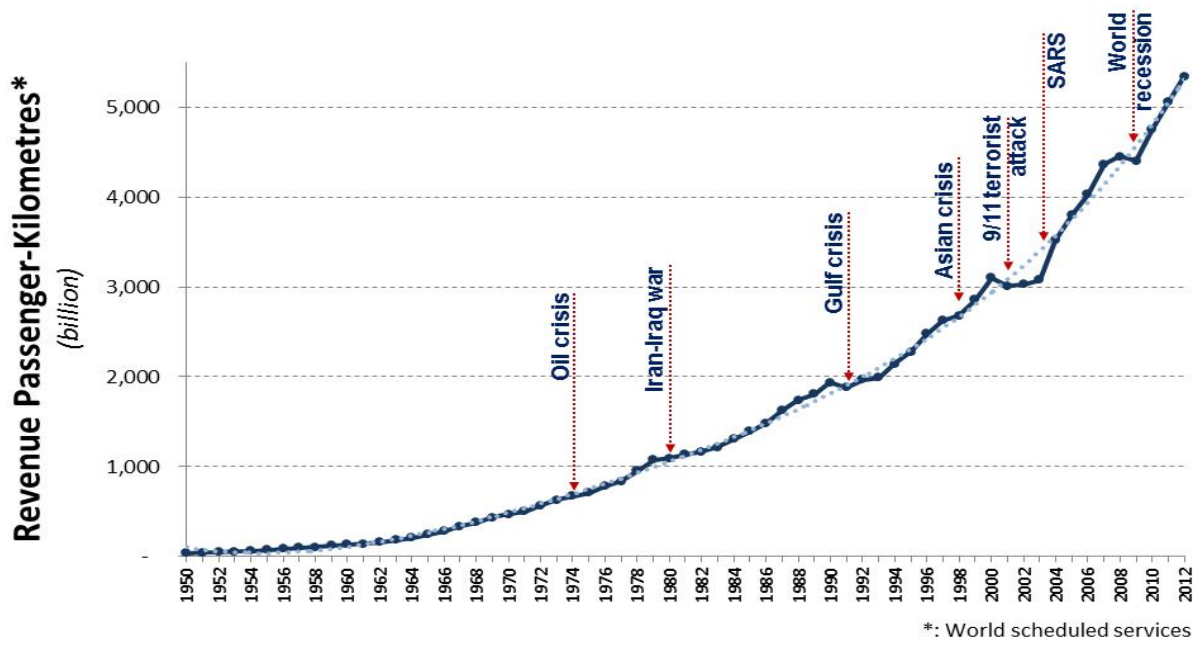

Source: International Civil Aviation Organization:

World Aviation and the World Economy

It took a couple years until finally everything got back to normal, and the intensity of air travel even superseded its past results.

In the European Union more and more people prefer flights to train or car travel, and we may experience the same in the United States too. Aviation is one of the busiest and safest way to travel. Carriers compete to each other in order to convince millions of passengers to choose their services. In this heavy competition, passengers may suffer harm by carriers in the form of breaching the travel contract. Based on this assumption, the European Union's legislative bodies enacted new rules for events like cancellation, delay and overbooking. Carriers shall pay a fix amount of compensation unless they successfully prove defenses. In the meantime, passengers are kept on board the plan for hours waiting to take off in the U.S. and they get nothing in terms of services or compensation.

Figure 2

Annual Growth in Global air Traffic Passengers Demand from 2005 to 2015

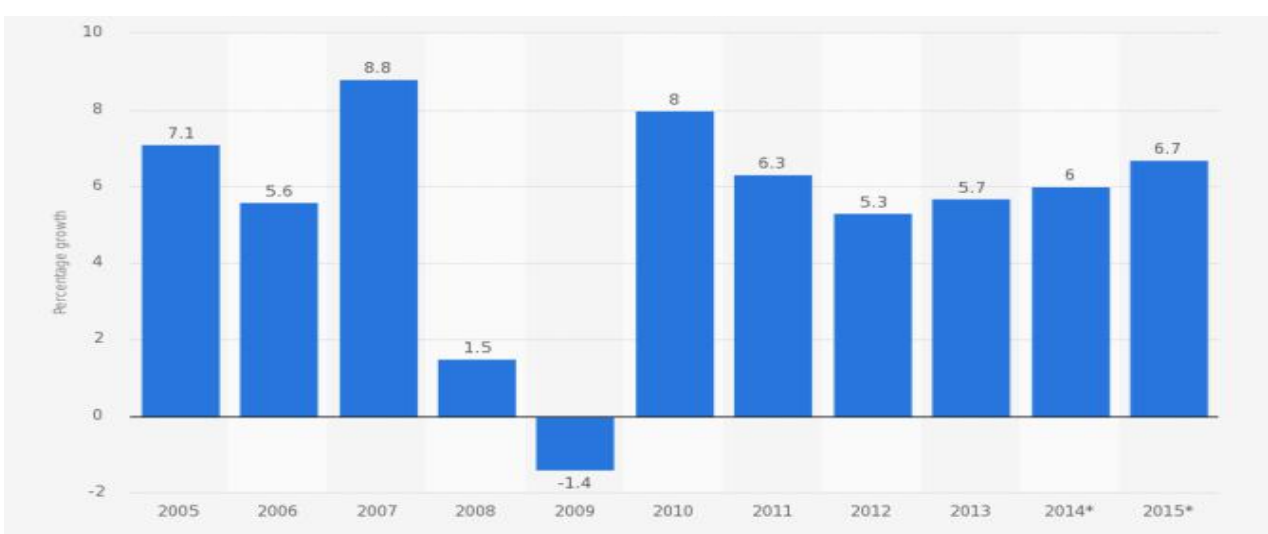

Source: IATA, ICAO, Federal Aviation Administration;

Statista - The Statistics Portal 2015 


\section{Air Passenger Rights in the EU}

This essay focuses on these situations and the development of passenger rights comparing the two systems to prove the European Union places more emphasis on the protection of passengers' interest and operate a more passenger friendly service system than the federal government of the United States.

In order to prove that the European Union gives more power to passengers, I would like to demonstrate how air carriers might exonerate themselves from liability using recent case law of the European Court of Justice. In case a flight was delayed or cancelled under the scope of the 261/2004/EC Regulation, it does not automatically mean that the carrier must pay compensation. The airline is obliged to do so only if the passengers reached their destination at least 3 hours later than it was originally scheduled, and there were no any extraordinary circumstances. First of all, we should clarify what time counts as relevant under the term "time of arrival". We may list four different circumstances that may qualify as "time of arrival". These events are the following:

$>$ the time that the aircraft lands on the runway ("touchdown"),

$>$ the time that the aircraft reaches its parking position and the parking brakes are engaged or the chocks have been applied ("inblock time"),

$>$ the time that the aircraft door is opened,

$>$ a time defined by the parties in the context of party autonomy.

There could be slight differences in these referred moments, and these several minute differences should decide whether the air carrier has breached the contract and, therefore, it is obliged to pay compensation to passengers. In the German wings $\mathrm{GmbH}$ versus Ronny Henning case (C452/13) the European Court of Justice got the opportunity to interpret this question and the underlying provisions. According to the ECJ, the time that the aircraft door is opened should be relevant in such cases as passengers may feel the end of the journey at that time. This is when the physical opportunity to leave the plane opens to all passengers.

After the question of breach of the contract has been decided, the airline may look for defenses and state that one of the following extraordinary circumstances was the underlying cause of the delay or the cancellation: political instability, meteorological conditions incompatible with the operation of the flight concerned, security risks, unexpected flight safety shortcomings, strikes that affect the operation of an operating air carrier and air traffic management decision.

In the essay I would like to analyze two of the six available defenses, namely the meaning and interpretation of the unexpected flight safety shortcomings and meteorological conditions incompatible with the operation of the flight concerned. They both seem to offer easy defenses under liability, however they are more complicated according to the recent case law of the European Court of Justice.

In order to get the true meaning of unexpected flight safety shortcomings, we have to examine two cases: the Friederike Wallentin - Hermann versus Alitalia - Linee Aeree Italiane SpA case (C-549/07) and the Sandy Siewert, Emma Siewert, Niele Siewert versus Condor Flugdienst GmbH case (C- 
394/14). In the first case Alitalia airline had some trouble with the engines and the plane delayed 24 hours. In the second case the flight was carried out with a six and half hours delay which was occurred because the aircraft which was due to operate the flight at issue had been damaged the previous evening at Stuttgart Airport. A set of mobile boarding stairs had collided with the aircraft, causing structural damage to a wing and, as a consequence, the aircraft had to be replaced. The two most important questions the court examined weather the airline could not, on any view, has been avoided the extraordinary circumstances by measures appropriate to the situation - that is to say, by measures which, at the time those extraordinary circumstances arise, meet, inter alia, conditions which are technically and economically viable for the air carrier concerned ${ }^{1}$ and the circumstances surrounding such an event can be characterized as 'extraordinary' within the meaning of Regulation only if they relate to an event which is not inherent in the normal exercise of the activity of the air carrier concerned and is beyond the actual control of that carrier on account of its nature or origin. ${ }^{2}$

Seeking for the interpretation of meteorological conditions incompatible with the operation of the flight concerned, I would like to demonstrate the Denies McDonagh versus Ryanair Ltd. case (C-12/11). Ms McDonagh booked a flight with Ryanair scheduled for 17 April 2010, for EUR 98. On 20 March 2010, the Eyjafjallajökull volcano in Iceland began to erupt. On 15 April right after the volcano entered an explosive phase the authorities closed the airspace over a number of Member States because of the risks to aircraft. Ms McDonagh flight was cancelled as well. During the period between 17 and 24 April Ryanair did not provide Ms McDonagh with care in accordance with the detailed rules laid down in Regulation. ${ }^{3}$ So the question was weather such a meteorological condition like a volcano eruption can be qualify as such vismaior circumstances in which airlines do not have to pay compensation and prove sufficient and reasonable care for their passengers. The ECJ stated the volcano eruption was a force majeure so the airline was not liable for delay in such cases, however it should have provided care of passengers event under such circumstances. That means airlines have to pay for accommodation and take reasonable care of passengers, in other words they have to cover the passenger's meals and hotel bill until they can fulfill their obligation and transport the passengers to the desired and contracted place of arrival.

\section{Conclusions}

Such a rigorous approach to the available defenses for air carriers may easily change the structure of competition in the European aviation market. It may have a significant impact on not only the ticket prices but on the mentality of passengers. We can already experience a change in passenger attitude. More and more disputes are carried out against airlines due to

\footnotetext{
${ }^{1}$ Judgment in Eglītis and Ratnieks, C- 294/10, paragraph 25

2 Judgment in Wallentin-Hermann, C-549/07, paragraph 23

${ }^{3}$ Article 9, Regulation No 261/2004
} 
insufficient services, and national courts are obliged to follow the interpretation of the ECJ as the Regulation shall be applied the same way in all Member States. The strict rules on passenger rights in the European market may also induce a change in the U.S. as well, and the competitiveness of American and European airlines may also suffer consequences of this improving concept of passenger rights in Europe.

List of References:

C-394/14 Sandy Siewert, Emma Siewert, Niele Siewert versus Condor Flugdienst $\mathrm{GmbH}$ case

C-452/13 German wings GmbH versus Ronny Henning case

C-12/11 Denies McDonagh versus Ryanair Ltd. case

C-294/10 Eglītis and Ratnieks case

C-549/07 Friederike Wallentin - Hermann versus Alitalia - Linee Aeree Italiane $\mathrm{SpA}$ case

Regulation (EC) No 261/2004 of the European Parliament and of the Council of 11 February 2004 establishing common rules on compensation and assistance to passengers in the event of denied boarding and of cancellation or long delay of flights, and repealing Regulation (EEC) No 295/91 